\title{
PRINCIPLE AND APPLICABILITY OF COSMIC-RAY NEUTRON METHOD FOR MEASURING SOIL MOISTURE
}

\author{
ZHAO, H. -ZHAO, Y. - WANG, F. Q.* - MA, D. F. \\ North China University of Water Resources and Electric Power \\ No.136, Jinshui Road, 450046 Zhengzhou, China \\ *Corresponding author \\ e-mail: wangfuqiang@ncwu.edu.cn \\ (Received 15 $5^{\text {th }}$ Jul 2017; accepted $19^{\text {th }}$ Dec 2017)
}

\begin{abstract}
Regional soil moisture monitoring has always been a difficult point in many researches. The traditional point measurement and the large scale remote sensing monitoring are always unable to obtain information of medium and small scale regional soil moisture. As a new type of mesoscale soil moisture condition monitoring method, the cosmic ray neutron method can obtain the soil moisture information within $300 \mathrm{~m}$ radius of the source region, which covers the shortage of the point measuring method and remote sensing method. This study utilized cosmic ray neutron instrument (CRS) to constantly monitor soil moisture, and conducted the applicability research of cosmic ray neutron method in soil moisture monitoring. Results show high consistency of CRS and time domain reflectometer (TDR) measurements, the fitting degree is 0.847 , the root mean square error is $0.020 \mathrm{~kg} / \mathrm{kg}$. Also, CRS is sensitive to precipitation, it can clearly show the increase of soil moisture under different conditions, while the sensitivity of TDR is relatively poor. This research can provide a reference for dynamic change monitoring of regional mesoscale soil moisture.
\end{abstract}

Keywords: soil moisture, CRS, TDR, mesoscale, precipitation

\section{Introduction}

At present, there are dozens of methods for measuring soil moisture, and traditional methods for measuring soil moisture include drying method, actual volumetric method, specific gravity method, ray method (Klenke et al., 1991), dielectric property method (Gong et al., 1997; Roth et al., 2004) and so on. Although these methods can accurately estimate the moisture content of soil profile, they are point measurement methods with small measurement scales, and measurement results can only represent the soil moisture status of this point, so spatial representation is small. Due to soil heterogeneity (Kim et al., 1997; Desilets et al., 2010), traditional point measurement methods can meet the requirements only by increasing to a larger area proportionally. Therefore, sufficient point measurement data are required for calculation, which greatly increases the cost and is only technically possible (Zreda et al., 2008; Hejazi et al., 2017). The use of remote sensing method for soil moisture monitoring at abroad began in the late 1960s, and in the 1970s, the study of soil moisture monitoring by remote sensing has achieved rapid and all-around development. Remote sensing technology has advantages such as fast aging, strong dynamic contrast, long-term dynamic large-area monitoring and good spatial-temporal resolution (Njoku et al., 1996), but it also has disadvantages such as shallow measuring depth, poor penetration, poor sensitivity, and short satellite flight life (Entekhabi et al., 2004; Andreasen et al., 2016; Hashemi, 2017).

In recent years, the technology of measuring regional soil moisture content using cosmic-ray neutron method has been rapidly developed. This method works based on the principle that cosmic-ray neutrons are moderated by the hydrogen atoms in soil 
water (Chrisman et al., 2013; Radan et al., 2017). The soil moisture content can be calculated only by passively measuring the intensity of neutrons near the ground after moderating (Villarreyes et al., 2011; Vazdani et al., 2017). It has characteristics such as large spatial coverage, and low requirements for soil salinity, soil density, soil texture and so on, and it can meet its power needs by using solar energy as energy, with the maximum measuring range of about $670 \mathrm{~m}$ and measuring depth of 12 76 cm (Gong et al., 1997; Desilets et al., 2013; Xiao et al., 2017). In this paper, nearly three months of continuous monitoring of soil moisture of Huibei Water Scientific Experiment Station, the East of Henan Water Conservancy Administration using a cosmic-ray neutron probe was conducted, and the results were compared and analyzed with the measurement results of TDR (Time Domain Reflectometry) to study the application of cosmic-ray neutron method in agricultural areas in the plains.

\section{Principle of cosmic-ray neutron method for measuring soil moisture}

\section{Technical principle}

The high-energy particle streams coming from the Milky Way Galaxy are captured into the atmosphere due to the Earth's magnetic field, and interact with the nuclei in the atmosphere to produce secondary cosmic rays, which collide with the nuclei in the soil to produce fast neutrons with 1-2 MeV of energy. These fast neutrons gradually collide with various nuclei in the atmosphere and the Earth's surface and thus are moderated, then become thermal neutrons with $0.025 \mathrm{eV}$ of energy and epithermal neutrons with 1$10 \mathrm{eV}$ of energy. One part of the moderated fast neutrons are absorbed by the soil and the other part the moderated fast neutrons are scattered into the air (Zreda et al., 2012; Yang et al., 2017).

The intensity of underground neutron is determined by two characteristics, namely soil scattering and soil absorption. The two most important soil scattering characteristics are: 1. Scattering cross section of material. 2. Average logarithmic energy attenuation per collision, namely effective collision times (Gong et al., 1997). Studies show that because the moderating power of hydrogen atoms exist widely in the soil in the nature, and hydrogen atoms exist in water, the greater the soil moisture, the greater the number of hydrogen atoms in the soil, and the stronger the capacity of soil to moderate and absorb fast neutrons, and the fewer the number of fast neutrons measured on the Earth's surface. Measurement of high heterogeneous soil using cosmic-ray neutron method showed that the neutron intensity was inversely proportional to soil moisture content (Chrisman et al., 2013). Therefore, the measurement of intensity of the moderated neutrons on the Earth's surface can well reflect the soil moisture content.

\section{Measuring range and depth}

The size of measuring range of CRS method did not depend on soil moisturecontent, instead, it was inversely proportional to atmospheric pressure (Chrisman et al., 2013). In thin air, the air density was small, and there is a small number of molecules per unit volume of air, so the propagation distance of neutrons was farther. Typically, the relationship between source zone radius and atmospheric pressure can be represented by Equation 1 (Jiao et al., 2013): 


$$
R=R_{0} \frac{P_{0}}{P}
$$

where $R_{0}$ was measuring radius under reference pressure $P_{0}(300 \mathrm{~m}$, radius under one standard atmospheric pressure, was usually used), $R$ was radius under current pressure $P$. The perennial mean pressure in the study area was about $10^{5} \mathrm{~Pa}$, and the calculations showed that the measuring radius of the source area was about $304 \mathrm{~m}$.

Measuring depth had a very strong correlation on soil moisture. Because the higher the soil moisture, the larger the number of hydrogen atoms in the soil, and the stronger the capacity of soil to moderate and absorb fast neutrons, thus, fast neutrons cannot continue to propagate downward, so the measuring depth was not very great. According to the simulative results of MCNPX (Monte Carlo N-Particle eXtended), the variant range of measuring depth was from $12 \mathrm{~cm}$ (simulated moisture content was $0.40 \mathrm{~m}^{3} / \mathrm{m}^{3}$ when soil was moist) to $76 \mathrm{~cm}$ (simulated moisture content was 0 when soil was dry) (Gong et al., 1997). The measuring depth can be obtained by calculation using Equation 2 proposed by Franz (Deng et al., 2007; Klenke et al., 1991):

$$
Z=\frac{5.8}{\frac{\rho_{b d}}{\rho_{w}} \tau+\theta_{m}+0.0829}
$$

where $\mathrm{Z}$ was effective measuring depth $(\mathrm{cm}) ; \rho_{b d}$ was soil bulk density $\left(\mathrm{g} / \mathrm{cm}^{3}\right) ; \rho_{w}$ was the density of liquid water, the default was $1 \mathrm{~g} / \mathrm{cm}^{3} ; \tau$ was lattice water content $(0 \sim 0.05$, the mass ratio of minerals in soil to bound water of soil particle, which was ignored in the calculation in this paper), and $\theta_{m}$ was the mass water content of soil $(\mathrm{kg} / \mathrm{kg})$.

\section{Correction method and inversion function}

Related researches showed that the propagation of fast neutrons is affected by many factors in addition to soil moisture, and factors having the most significant effect on the propagation of fast neutrons are atmospheric pressure and atmospheric vapor.

\section{(1) Atmospheric pressure correction}

For a certain source region, the higher the atmospheric pressure, the greater the density of gas molecules, the greater the chance that fast neutrons collided with atmospheric particles, and the lower the intensity of neutrons near the ground measured by neutron probe, on the contrary, the lower the atmospheric pressure, the higher the intensity of neutrons near the ground measured by neutron probe, thereby leading to error of calculated results. The effects of atmospheric pressure can be corrected by using correction coefficient $f_{p}$ (Villarreyes et al., 2011) as shown in Equation 3:

$$
f_{p}=\exp \frac{P-P_{0}}{L}
$$


where $P$ was atmospheric pressure during sampling; $P_{0}$ was mean atmospheric pressure during the experiment; $L$ was mass attenuation length of high-energy neutron, which was $128 \mathrm{~g} / \mathrm{cm}^{2}$ in high latitude region and $142 \mathrm{~g} / \mathrm{cm}^{2}$ in low latitude region, during the period it showed progressive change.

\section{(2) Atmospheric vapor correction}

Through experiment, Rosolem et al. (2013) concluded that the intensity of neutrons near the ground measured by neutron probe was completely determined by the soil moisture when the air did not contain any atmospheric vapor, while the intensity of fast neutrons near the ground measured by neutron probe was affected at different levels when the air contained different levels of atmospheric vapor. Therefore, he put forward Equation 4 of atmospheric vapor correction coefficient $(C W V)$ to correct atmospheric vapor:

$$
C W V=1+0.0051\left(\rho-\rho_{0}\right)
$$

where $\rho$ was the actual density of atmospheric vapor $\left(\mathrm{g} / \mathrm{m}^{3}\right) ; \rho_{0}$ was the absolute density of atmospheric vapor on the Earth's surface, which usually took 0.

To sum up, the intensity of fast neutrons after atmospheric pressure correction and atmospheric vapor correction was finally obtained (Eq. 5):

$$
N=N_{\text {raw }} \cdot f_{p} \cdot C W V
$$

where $\mathrm{N}$ was the intensity of fast neutrons after atmospheric pressure correction and atmospheric vapor correction; $\mathrm{N}_{\text {raw }}$ was the original intensity of fast neutrons measured by neutron probe (Heidbüchel et al., 2015).

\section{Introduction to the study area}

In this study, Huibei Water Scientific Experiment Station, the East of Henan Water Conservancy Administration was chosen as the study area. Located in Xinglong Village, Kaifeng County, Henan Province, $114^{\circ} 35^{\prime}$ east longitude, $34^{\circ} 40^{\prime}$ north latitude, it is formed by alluvion of the Yellow River, featuring low and flat, mostly clay, loam and sandy soil, single underlying surface condition, suitable for crop cultivation. It has warm temperate continental monsoon climate, with an annual average temperature of $14.52{ }^{\circ} \mathrm{C}$, most rain falling between June and September, and an annual mean precipitation of $662.8 \mathrm{~mm}$. During the experiment of April 2016 July 2016, wheat and corn were planted in the source region.

\section{Material and methods}

\section{Sampling and determination of measuring depth}

(1) During the experiment, soil samples $50 \mathrm{~m}, 100 \mathrm{~m}, 200 \mathrm{~m}, 300 \mathrm{~m}$ in the east, south, west, north of the cosmic-ray neutron probe were taken and treated, and the sampling depths were $0 \sim 10 \mathrm{~cm}, 10 \sim 20 \mathrm{~cm}$ and $20 \sim 30 \mathrm{~cm}$, respectively. The location of 
the cosmic-ray neutron probe and the distribution of the sampling points are shown in Figure 1.

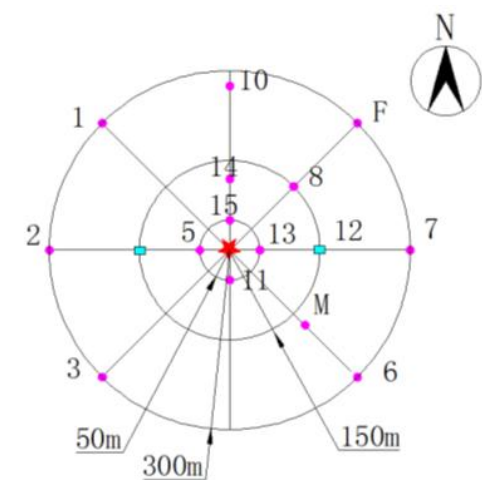

a

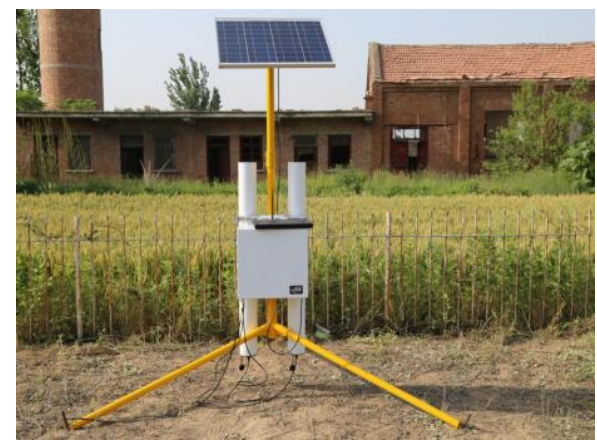

b

Figure 1. (a) The location of instrument and sampling points: red star denotes cosmic-ray moisture senser; dots represent 14 locations in CRS footprint; rectangles represent time domain reflectometry. (b) The location of the cosmic-ray sensing probe

Soil moisture content (the arithmetic average of multiple sampling points within measuring range) and oil bulk density were obtained by calculation after drying and weighing, $29 \mathrm{~cm}$, effective measuring depth of CRS was obtained by calculation by Equation 2.

(2) According to the measuring range and effective measuring depth of CRS, a sampling point $150 \mathrm{~m}$ in the east and west of the cosmic-ray neutron probe were chosen respectively using the existing TDR device in the study area, and moisture probes were placed in three levels, namely $0 \sim 10 \mathrm{~cm}, 10 \sim 20 \mathrm{~cm}$ and $20 \sim 30 \mathrm{~cm}$, and the arithmetic average of data measured by TDR was conducted and then converted into mass water content.

\section{Parameter calibration}

Desilets et al. (2010) created a function relationship between the number of neutrons an soil moisture on the basis of MCNPX (Monte Carlo N-Particle eXtended) model, as shown in Equation 6:

$$
\theta(N)=\frac{\alpha_{0}}{\frac{N}{N_{0}}-\alpha_{1}}-\alpha_{2}
$$

where $\theta(N)$ was the mass water content of soil $(\mathrm{kg} / \mathrm{kg}) ; N$ was the number of fast neutrons after atmospheric pressure correction and atmospheric vapor correction; $N_{0}$ was the number of fast neutrons when the air in the sane source region did not contain any atmospheric vapor, which was a constant value; $\alpha_{0}, \alpha_{1}, \alpha_{2}$ were parameters, and $\alpha_{0}=0.0808, \alpha_{1}=0.372, \alpha_{2}=0.115$ when the soil moisture content was greater than $0.02 \mathrm{~kg} / \mathrm{kg}$. 
By using the number of fast neutrons in the source region after atmospheric pressure correction and atmospheric vapor correction and the soil moisture content after conducting arithmetic average method using weighing method, and $\mathrm{N}_{0}$ can be obtained through inverse deduction.

\section{Results analysis and discussion}

According to $N_{0}$ after parameter calibration and Equation 6, changes in soil moisture of the source region per hour from April 27, 2016 to July 7, 2016 were obtained by calculation. By comparing CRS data and TDR observation results, the following conclusions can be drawn:

(1) Figure 2 shows that the soil moisture content range measured by CRS was $0.11 \sim 0.21 \mathrm{~kg} / \mathrm{kg}$, with an average soil moisture content of the source region of $0.15 \mathrm{~kg} / \mathrm{kg}$; the soil moisture content range measured by TDR was $0.12 \sim 0.17 \mathrm{~kg} / \mathrm{kg}$, with an average soil moisture content of $0.14 \mathrm{~kg} / \mathrm{kg}$. Thus, the monitoring results of the two were consistent. Among which, the data with absolute error smaller than $0.01 \mathrm{~kg} / \mathrm{kg}$ accounted for $51.42 \%$ of total data, and the data with absolute error greater than $20 \%$ accounted for $12.92 \%$ of total data, their fitting degree was 0.847 (Fig. 3), and root mean square error (RSME) was $0.020 \mathrm{~kg} / \mathrm{kg}$. It showed that the soil moisture content range measured by CRS was quite consistent with that measured by TDR, thereby providing real-time soil moisture conditions for farm management decisions to meet the needs of production practice.

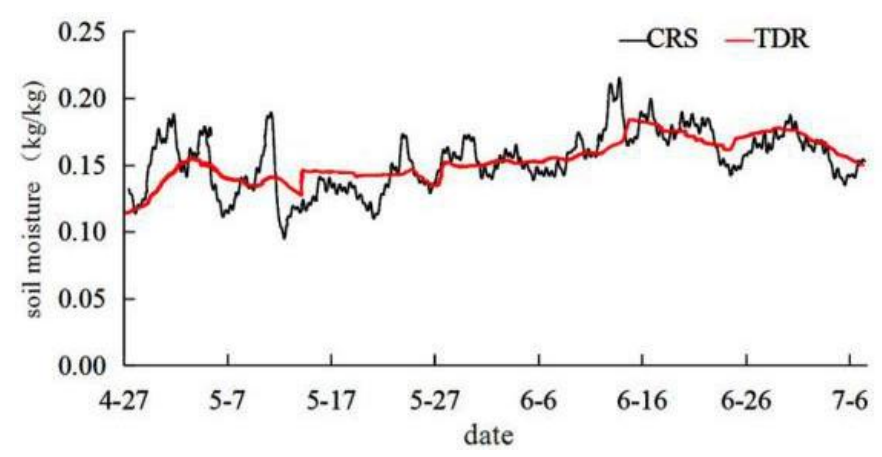

Figure 2. The comparison of CRS and TDR soil moisture in experiment period

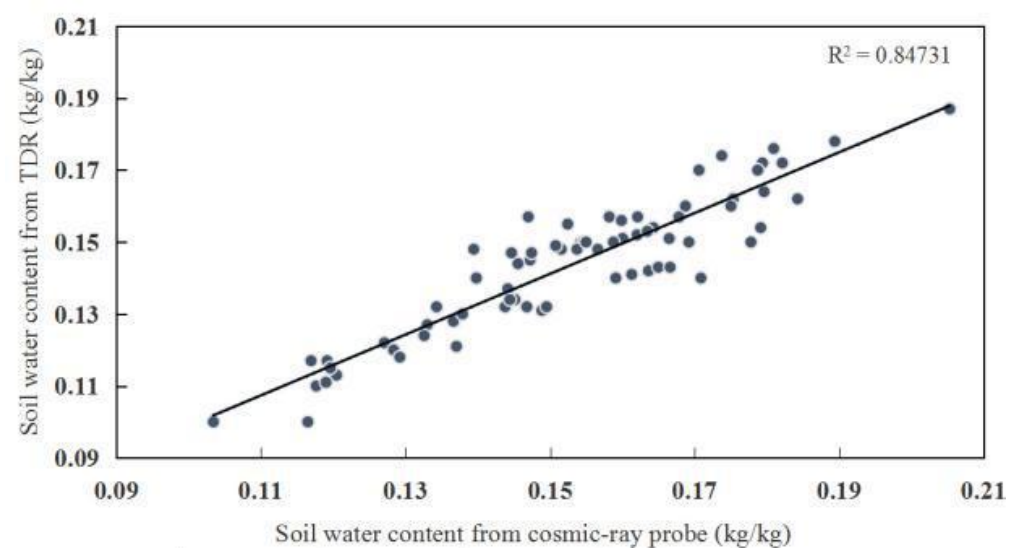

Figure 3. The comparison of CRS and TDR daily soil moisture in experiment period 
(2) Figure 4 shows that during the experiment there were 16 rainfalls, regardless of the size of rainfall, CRS had good responsiveness to each rainfall, namely, the soil moisture content immediately increased when there was a rainfall, and the response lag time was about $1 \mathrm{~h}$; while TDR only responded to four large rainfalls (May 14, May 27, June 14 and June 24), with soil moisture content range of $0.01 \sim 0.02 \mathrm{~kg} / \mathrm{kg}$, and did not respond to small rainfalls. Thus, the following conclusions can be drawn: CRS had more sensitive response to different rainfall events compared with TDR, and can better reflect the changes in soil moisture corresponding to the rainfall.

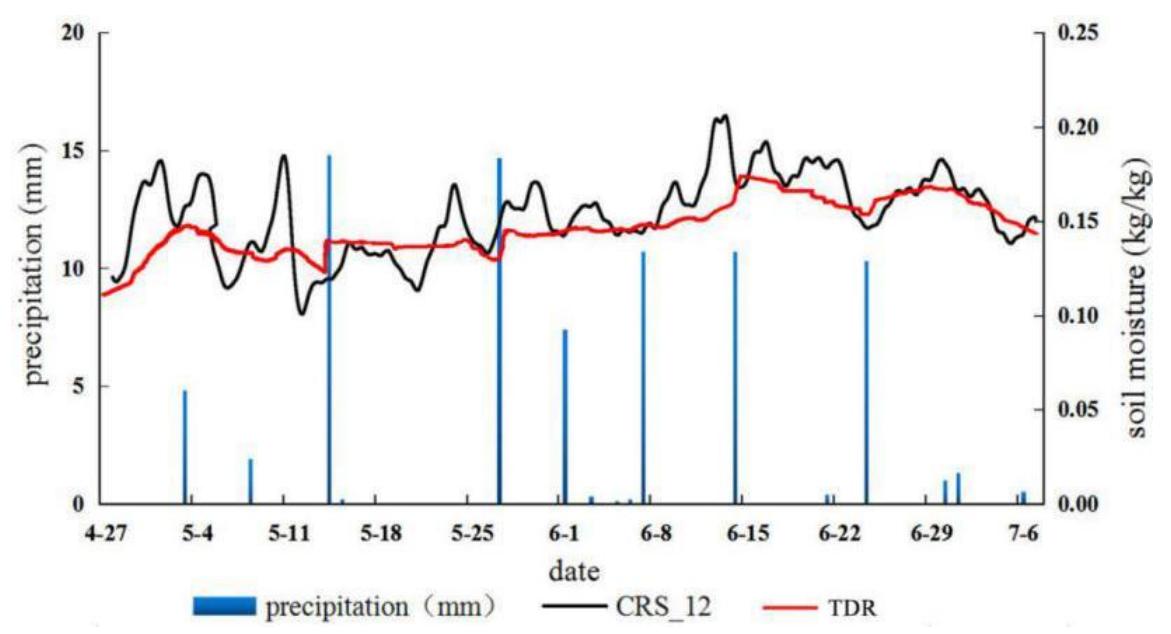

Figure 4. The response of $C R S$ and TDR for precipitation in experiment period

\section{Conclusion}

The cosmic-ray neutron method had many advantages in determination of soil moisture: low requirements for soil type, a mesoscale, non-invasive and non-contact measurement mode, without radioactive sources, easy to be automated, and can be combined well with remote sensing technology. This technology can bridge the traditional gap between traditional point measurement and remote sensing large-scale detection.

Through nearly three months of analysis of CRS, TDR and other related meteorological factors, the following conclusions can be drawn: the cosmic-ray neutron probe had good applicability in agricultural areas in the plains. The soil moisture content range measured by CRS was quite consistent with that measured by TDR, their fitting degree was 0.847 , and root mean square error (RSME) was $0.020 \mathrm{~kg} / \mathrm{kg}$; in addition, though CRS and TDR can perform automatic and continuous monitoring of soil moisture, CRS had more sensitive response to different rainfall events compared with TDR, and can better reflect the changes in soil moisture corresponding to the rainfall, while TDR only responded to large rainfalls, and did not respond to small rainfalls. The cosmic-ray soil moisture observation system can accurately measure the soil moisture of mesoscale farmland and its dynamic change, thereby providing basis for farm management decisions.

In the experiment, in addition to the influence of atmospheric pressure and atmospheric vapor on the calculated results of CRS, the plants, microorganisms and 
humus on the underlying surfaces in the source region can also have an influence on the propagation of fast neutrons, and at present there is no perfect method to correct these influences. The effects caused by lattice water and water inorganic matter can be eliminated by the first field soil moisture correction (Zreda et al., 2012). For the problems in the cosmic-ray neutron method for measuring oil moisture, a more rational function formula to be created is the emphasis and difficulty for further promotion of the cosmic-ray neutron method.

Acknowledgements. The authors acknowledge the National Key Research and Development Program of China (2016YFC0401401), the Major Research Plan of the National Natural Science Foundation of China (91547209), the National Natural Science Foundation of People's Republic of China (51579101, 51709111), and the Science-tech Innovation Talents in University of Henan province (15HASTIT044). The authors would like to express their sincere gratitude to the anonymous reviewers for their constructive comments and useful suggestions that helped us improve our paper.

\section{REFERENCES}

[1] Andreasen, M., Jensen, K. H., Zreda, M. et al. (2016): Modeling cosmic ray neutron field measurements. - Water Resources Research 52(8): 6451-6471.

[2] Chrisman, B., Zreda, M. (2013): Quantifying mesoscale soil moisture with the cosmic-ray rover. - Hydrology \& Earth System Sciences Discussions 10(6): 7127-7160.

[3] Deng, Y. C., Xu, Y. H. (2007): Introduction to the methods of soil moisture content measuring. - China Hydrology 27(4): 20-24.

[4] Desilets, D., Zreda, M. (2013): Footprint diameter for a cosmic-ray soil moisture probe: Theory and Monte Carlo simulations. - Water Resources Research 49(6): 3566-3575.

[5] Desilets, D., Zreda, M., Ferré, T. P. A. (2010): Nature's neutron probe: Land surface hydrology at an elusive scale with cosmic rays. - Water Resources Research 46(11): W11505.

[6] Entekhabi, D., Njoku, E. G., Houser, P. et al. (2004): The hydrosphere State (hydros) Satellite mission: an Earth system pathfinder for global mapping of soil moisture and land freeze/thaw. - IEEE Transactions on Geoscience \& Remote Sensing 42(10): 2184-2195.

[7] Franz, T. E., Zreda, M. Ferre, T. P. A. et al. (2012): Measurement depth of the cosmic ray soil moisture probe affected by hydrogen from various sources. - Water Resources Research 48(8): 9200-9200.

[8] Franz, T. E., Wang, T., Avery, W., Finkenbiner, C., Brocca, L. (2015): Combined analysis of soil moisture measurements from roving and fixed cosmic ray neutron probes for multiscale real-time monitoring. - Geophysical Research Letters 42(9): 3389-3396.

[9] Gong, Y., Li, Z., Liao, C. et al. (1997): Measurement of field soil water by using time domain reflectometry. - Advances in Waterence 8(4): 329-334.

[10] Hashemi, N. (2017): Recognizing the potential of sustainable use of pasture resources in south khorasan province with approch of carrying capacity. - Environment Ecosystem Science 1(2): 09-12.

[11] Heidbüchel, I., Güntner, A., Blume, T. (2015): Use of cosmic ray neutron sensors for soil moisture monitoring in forests. - Hydrology \& Earth System Sciences Discussions 12(9): 9813-9864.

[12] Hejazi, S. M., Lotfi, F., Fashandi, H., Alirezazadeh, A. (2017): Serishm: an eco-friendly and biodegradable flame retardant for fabrics. - Environment Ecosystem Science 1(2): 05-08.

[13] Jiao, Q., Zhu, Z., Liu, S. et al. (2013): Research and application of cosmic-ray fast neutron method to measure soil moisture in the field. - Advances in Earth Science 28(10): 1136-1143. 
[14] Kim, C. P., Stricker, J. N. M., Feddes, R. A. (1997): Impact of soil heterogeneity on the water budget of the unsaturated zone. - Water Resources Research 33(5): 991-999.

[15] Klenke, J. M., Flint, A. L. (1991): Collimated neutron probe for soil water content measurements. - Soil Science Society of America Journal 55(4): 916-923.

[16] Njoku, E. G., Entekhabi, D. (1996): Passive microwave remote sensing of soil moisture. Journal of Hydrology 184(1): 101-129.

[17] Radan, A., Latifi, M., Moshtaghie, M., Ahmadi, M., Omidi, M. (2017): Determining the sensitive conservative site in Kolah Ghazi National Park, Iran, in order to management wildlife by using GIS software. - Environment Ecosystem Science 1(2): 13-15.

[18] Rosolem, R., Shuttleworth, W. J., Zreda, M. et al. (2013): The Effect of atmospheric water vapor on neutron count in the cosmic-ray soil moisture observing system. - Journal of Hydrometeorology 14(5): 1659-1671.

[19] Roth, K., Wollschlager, U., Cheng, Z. H., Zhang, J. B. (2004): Exploring Soil Layers and Water Tables with Ground-Penetrating Radar. - Pedosphere 14(3): 273-282.

[20] Vazdani, S., Sabzghabaei, G., Dashti, S., Cheraghi, M., Alizadeh, R., Hemmati, A. (2017): FMEA techniques used in environmental risk assessment. - Environment Ecosystem Science 1(2): 16-18.

[21] Villarreyes, C. A. R, Baroni, G., Oswald, S. E. (2011): Integral quantification of seasonal soil moisture changes in farmland by cosmic-ray neutrons. - Hydrology \& Earth System Sciences 15(12): 3843-3859.

[22] Xiao, H., Wang, M., Sheng, S. (2017): Spatial evolution of URNCL and response of ecological security: a case study on Foshan City. - Geology, Ecology, and Landscapes 1(3): 190-196.

[23] Yang, S., Li, J., Song, Y. (2017): Application of surfactant Tween 80 to enhance Fenton oxidation of polycyclic aromatic hydrocarbons (PAHs) in soil pre-treated with Fenton reagents. - Geology, Ecology, and Landscapes 1(3): 197-204.

[24] Zreda, M. Desilets, D., Ferré, T. P. A. et al. (2008): Measuring soil moisture content non-invasively at intermediate spatial scale using cosmic-ray neutrons. - Geophysical Research Letters 35(21): L21402.

[25] Zreda, M. Shuttleworth, W. J., Zeng, X. et al. (2012): COSMOS: the COsmic-ray Soil Moisture Observing System. - Hydrology \& Earth System Sciences 16(11): 4079-4099. 